\title{
SIGNA
}

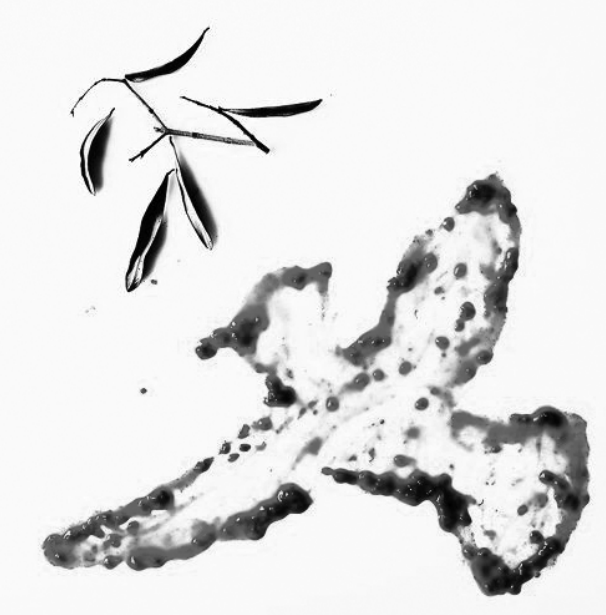

REVISTA DE LA ASOCIACIÓN ESPAÑOLA DE SEMIÓTICA

2011

20

CENTRO DE INVESTIGACIÓN DE SEMIÓTICA LITERARIA, TEATRAL Y NUEVAS TECNOLOGÍAS.

ISSN 1133-3634

UחED Editorial

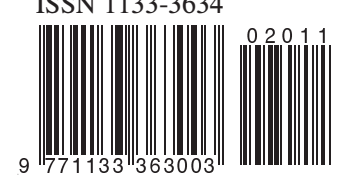

DEPARTAMENTOS DE LITERATURA ESPANOLA Y TEORÍA DE LA LITERATURA Y FILOLOGÍA FRANCESA

UNED 


\section{EL CORRESPONSAL DEL CENSOR}

\section{Manuel RUBÍN DE CELIS}

Edición de Klaus-Dieter Estler, Renate Hodab e Inmaculada Urzainqui (Madrid: Iberoamericana-Vervuert, 2009).

Cada vez es mayor el interés por la prensa del siglo XVIII, y cada día son más los estudios de los diarios, que fueron sin duda el medio que mejor se hizo eco de los intereses de la incipiente burguesía. Rescatar y reeditar algunos aquellos periódicos ayuda a tener un panorama más completo del nacimiento y desarrollo de este medio de comunicación, de sus raíces literarias y de cómo fue alcanzando sus propias entidades y características. Ediciones como la que se reseña de Klaus-Dieter Estler, Renate Hodab e Inmaculada Urzainqui de El Corresponsal del Censor, junto con otras anteriores, como la de Caso González de El Censor (1989), la de Yolanda Arencibia de El Pensador (1999), la de Inmaculada Urzainqui de La Pensatriz Salmantina (2004) o la de Scott Dale de La Pensadora Gaditana (2005) contribuyen a comprender mejor, a tener presente y a mano esta literatura fragmentada del Setecientos.

La brevedad, agilidad y actualidad que caracterizó a estos textos fueron herramientas claves para catalizar las nuevas formas de expresión y de relación social. Su variedad temática, carácter especulativo, sencillez y novedad 
comunicativas resultaron atractivos tanto para los que vinieron a llamarse escritores públicos o diaristas como para los lectores o «espectadores» de la época. Unos y otros como representantes de una manera diferente de explicar y de aprehender la realidad por medio de pequeñas piezas que componen y reflejan un todo: el mapa del nuevo régimen.

El Corresponsal del Censor (1786-1788) se suma a la corriente de periódicos de crítica moralista, iniciada por la prensa inglesa con The Tatler o The Spectator. En España estos Espectadores o Semanales morales tuvieron como primer representante a El Pensador, quien recogió el testigo de esta veta periodística y preparó el terreno para la aparición de El Censor. El paso de uno a otro periódico fue significativo: de los moderados «Pensamientos» del primero a los críticos «Discursos» del segundo. Y es precisamente en esta transmutación donde se fue conformando la figura del crítico como una de las ramas posibles de la actividad periodística. Una actitud crítica frente a la sociedad que se recogía en discursos sociales que a modo de relatos, viajes, cartas y pseudobiografías mostraban las impresiones, problemas y discusiones de una época en la que todo se ponía en tela de juicio y en la que todo principio era revisado; toda ley debatida; y toda nueva forma de comportamiento, desarrollada. El crítico, como el periodista, fue el nuevo modelo de escritor que mejor representó el progreso y el proceso de modernidad del Setecientos.

Manuel Rubín de Celis, como José Clavijo y Fajardo, Luis García Cañuelo y Luis Pereira, representaron con sus respectivas apuestas periodísticas este nuevo tipo de escritor de clase media que encontró en la prensa el medio de expresión y de manutención. Los diarios fueron los que mejor representaron ese salto de mentalidad que supuso entender la palabra como moneda de cambio. Y los periodistas, los primeros que entendieron que su producción conllevaba una recompensa económica. Un autor que entiende su trabajo en función de un público al que se debe y que tiene que tener presente en su proceso de escritura. Estos escritores públicos generaban opinión, reflejaban los problemas de la calle en los diarios; moralizaban sobre lo que estaba bien y lo que estaba mal; y sacaban a la palestra las costumbres, las discusiones de los cafés y de las tertulias, tan a la moda en la época.

Estos periodistas se hacían eco de la realidad desde la sencillez y la brevedad, pero, sobre todo, lo que se aprecia en sus textos es el tono conversacional propio de estas reuniones. Rubín de Celis, como otros diaristas, piensa en el mayor número de lectores posibles, probablemente por convicción, pero también, porque de ello dependía su sueldo. El periodista, como ya ocu- 
rriera antes con el dramaturgo, se convierte en otro catalizador social, que dependía del público para quien escribía. Por ello, no es de extrañar que muchos de los escritores de diarios fueran también dramaturgos, como Luciano Francisco Comella, editor del Diario de las Musas.

Al contar con la edición completa e impresa en un único volumen de $E l$ Corresponsal del Censor, como ocurre con las colecciones y ediciones de artículos de periodistas y columnistas actuales, se crea una visión de conjunto, de unidad, que si, por un lado, nos permite reparar en aspectos que de otro modo se nos escaparían, o nos parecerían más desarticulados, por otro lado, nos da la impresión de estar frente a un libro, por lo que se nos diluyen los criterios de periodicidad y eventualidad con los que fueron construidos y publicados estos escritos.

La visión de conjunto pone de relieve el apego a las fórmulas literarias de este diario. El recurso de la carta como único formato que ahorma todos sus textos. Recurso que le permite al escritor establecer el modelo de diálogo y el tono conversacional necesario, al tiempo que le une a la fuerte tradición epistolar del XVIII. Todas estas epístolas se inician con unos breves versos, recogidos de diferentes autores y pensadores, que son el preámbulo, el lema y la síntesis del mensaje de cada una de ellas. La carta que dinamiza la escritura y que juegan a su vez con la ficción de varios interlocutores. Distintas voces que se esconden bajo pseudónimos significativos como Simplicio Manso, El amigo de la Paz, El Observador, Leocadia Matute o María de los Dolores, y otros anónimos, que forman parte de los textos y que responden a la opinión de algún tertuliano de café, reunión, o baile. El propio Corresponsal se esconde tras el nombre de Ramón Harnedo y es quien mejor representa al nuevo tipo de escritor público, erudito a la violeta si se quiere, hombre a la moda, conocedor de las novedades y preocupado por las modas, asiduo a cafés, al Prado, etc.

Mitad parodia de estas nuevas costumbres, mitad reflejo y asunción de las mismas, bel esprit y hombre de letras del XVIII. Como señala Renate Hodab en su introducción, el retrato de Ramón Harnedo aparece en dos ocasiones en estos textos. Primero, es el propio autor ficticio quien se presenta en el segundo de sus discursos y después, es un lector quien nos lo describe, en la duodécima carta. Y no es baladí que se produzca este retrato: casi todos los periódicos de la época se vieron obligados a describir en sus primeros números qué era un periodista y cuál era su función. Pero la peculiar apuesta ficcional de El Corresponsal del Censor, al inventarse al crítico Ramón Harnedo, obliga más que a explicar la función periodística del mismo, a des- 
cribir al personaje inventado. Este diario se instala con comodidad en esquemas literarios que recuerdan algunos de los personajes, puntos de vista y temáticas de José Cadalso en sus Cartas Marruecas o en Los eruditos a la violeta.

La crítica de costumbres de estos discursos de El Corresponsal del Censor no sorprende al lector habitual de la prensa o teatro popular del Setecientos. Son los mismo tópicos, los mismos modelos de sociabilidad los que se ponen en tela de juicio: los nuevos hábitos de la mujeres, su actitud, los matrimonios de conveniencia, las reglas neoclásicas aplicadas a la literatura, la educación, la formación de las universidades, la reforma de las leyes penales, la pedantería, la ociosidad, etc. En ocasiones, parece que estemos asistiendo a la representación de un sainete o fin de fiesta de la época, con sus petimetres. Tanto por el protagonismo que adquieren estos personajes, autores-lectores de El Corresponsal, como por la sencillez expresiva y la reiteración de argumentos. Desde un punto de vista actual, este diario está mucho más cerca de la ficción puramente literaria que otros periódicos como El Pensador o El Censor. Sin embargo, el uso de los pseudónimos, especialmente el de Ramón Harnedo, el juego de interlocutores, el desarrollo de lo anecdótico y la dinamización de los textos por medio de diálogos, o la escenificación de lo público, preludia el articulismo posterior de Mariano José de Larra.

Los estudios introductorios de esta edición resultan muy útiles y certeros. Kaus-Dieter Ertler contextualiza El corresponsal del Censor dentro de la prensa moral europea de la época, lo que nos permite una vez más comprobar el caldo de cultivo común existente en la Europa en el Setecientos: tendencias, preocupaciones e intereses de los que España participa y a los que no fue ajeno este país en absoluto. Inmaculada Urzainqui se ocupa del personaje de Manuel Rubín de Celis, de su devenir vital y de su producción. Pone al día lo que se conocía de este escritor, entre otras cosas por su trabajo Periodismo e Ilustración en Manuel Rubín de Celis (1983). Y Renate Hodab se encarga del análisis más estructural y literario de las cartas que componen el periódico, de su autor ficticio, de los lectores y de la crítica de costumbres. Los editores han incluido además el conocido Diálogo céltico transpirenaico, de Manuel Rubín de Celis, publicado en las mismas fechas del periódico. La bibliografía y los índices finales del volumen centran y facilitan la labor de los estudiosos.

María Angulo Egea 